\title{
Interleukin-15 Receptor Is Essential to Facilitate GABA Transmission and Hippocampal-Dependent Memory
}

\author{
Yi He, ${ }^{1}$ Hung Hsuchou, ${ }^{1}$ Xiaojun Wu, ${ }^{1}$ Abba J. Kastin, ${ }^{1}$ Reas S. Khan, ${ }^{1}$ Paul J. Pistell, ${ }^{1}$ Wei-Hsung Wang, ${ }^{2}$ Jiming Feng, ${ }^{3}$ \\ Zengbiao Li, ${ }^{4}$ Xiaochuan Guo, ${ }^{4}$ and Weihong Pan $^{1}$ \\ ${ }^{1}$ Pennington Biomedical Research Center, Baton Rouge, Louisiana 70808, ${ }^{2}$ Department of Physics and ${ }^{3}$ School of Veterinary Medicine, Louisiana State \\ University, Baton Rouge, Louisiana 70803, and ${ }^{4}$ Drumetix Laboratories, Greensboro, North Carolina 27409
}

Interleukin-15 (IL15) is a cytokine produced by normal brain, but the functions of the IL15 system in normal adults are not yet clear. The hypothesis that the hippocampal IL15 system is essential for memory consolidation was tested by use of IL15R $\alpha$ knock-out mice in behavioral, biochemical, immunohistological, and electron microscopic analyses. The knock-out mice showed deficits in memory, determined by the Stone T-maze and fear conditioning. In their hippocampi, the concentration of GABA was significantly lower. There were region-specific changes of the GABA-synthesizing enzyme glutamic acid decarboxylase (GAD), with increased GAD-67immunopositive interneurons in the stratum oriens of the CA1 region of the hippocampus, accompanied by nonsignificant reduction of GAD-67 synapses in the CA3 region. Western blotting showed an increase of GAD-65, but not GAD-67, in the hippocampal homogenate. The ultrastructure of the hippocampus remained intact in the knock-out mice. To further test the hypothesis that IL15 directly modulates GABA turnover by reuptake mechanisms, the dose-response relationship of IL15 on ${ }^{3} \mathrm{H}-\mathrm{GABA}$ uptake was determined in two neuronal cell lines. The effective and nontoxic dose was further used in the synaptosomal uptake studies. IL15 decreased the uptake of ${ }^{3} \mathrm{H}-\mathrm{GABA}$ in synaptosomes from the forebrain of wild-type mice. Consistent with this, IL15R $\alpha$ knock-out mice had increased synaptosomal uptake of ${ }^{3} \mathrm{H}-\mathrm{GABA}$. Overall, the results show novel functions of a unique cytokine in normal hippocampal activity by regulating GABA transmission.

\section{Introduction}

The immunomodulatory cytokine interleukin-15 (IL15) is ubiquitously present in the normal CNS as well as other organs (Maślińska, 2001). Yet, the functions of the IL15 system in the normal brain are not clear. Based on the abundance of IL15 and its specific receptor IL15R $\alpha$ in the hippocampus, we tested the hypothesis that IL15 facilitates hippocampal-dependent memory consolidation.

IL15 is a $14 \mathrm{kDa}$ cytokine belonging to the four- $\alpha$-helix bundle family of cytokines that also includes IL2, leukemia inhibitory factor, and several other interleukins. In particular, IL15 and IL2 share two receptor subunits (IL2R $\beta$ and IL2R $\gamma \mathrm{c}$ ), while IL15 also binds to its unique receptor $\alpha$-subunit. IL15 signaling is most effective through the heterotrimeric complex, with activation of Janus kinases (JAKs) and signal transducer and activator of transcription (STAT) proteins. Studies of models of rheumatoid arthritis have shown a distinct role of IL15 in immunomodulation that cannot be replaced by the cognate cytokine IL2 (McInnes et al., 1997; Kobayashi et al., 2000; Budagian et al., 2006). IL15R $\alpha$ knock-out $(\mathrm{KO})$ mice are viable and fertile, but have lymphope-

Received Dec. 12, 2009; revised Feb. 6, 2010; accepted Feb. 26, 2010.

Grant support was provided by the National Institutes of Health (NS62291 and NS45751 to W.P., and DK54880 to A.J.K.). We appreciate the technical assistance on electron microscopic studies from Ying Xiao (The Socolofsky Microscopy Facility, Department of Biological Sciences, Louisiana State University, Baton Rouge, LA).

Correspondence should be addressed to Dr. Weihong Pan, Blood-Brain Barrier Group, Pennington Biomedical Research Center, 6400 Perkins Road, Baton Rouge, LA 70808. E-mail: weihong.pan@pbrc.edu.

DOI:10.1523/JNEUROSCI.6160-09.2010

Copyright $\odot 2010$ the authors $\quad 0270-6474 / 10 / 304725-10 \$ 15.00 / 0$ nia and reduced NK, NK T, CD ${ }^{+} \mathrm{T}, \mathrm{TCR} \delta / \gamma$-IELs, and memory $\mathrm{CD}^{+}{ }^{+} \mathrm{T}$ cells (Lodolce et al., 1998).

Very few reports have addressed the role of IL15 in the brain. A study in IL2 KO mice suggests that IL15 might be involved in hippocampal neurogenesis (Beck et al., 2005). In rabbits, high doses of IL15 induce dose-dependent increases in non-REM sleep after intracerebroventricular injection (Kubota et al., 2001). Cellular studies show that IL15 is produced by astrocytes, microglia, and neurons, and can be upregulated by the proinflammatory cytokines TNF, IL1 $\beta$, and interferon $\gamma$ (Lee et al., 1996; Hanisch et al., 1997; Satoh et al., 1998).

Study of the normal cerebral function of the IL15 system has important implications in neuroinflammation. IL15 is elevated in serum and CSF of patients with active multiple sclerosis (Rentzos et al., 2006). In a mouse autoimmune model of multiple sclerosis, experimental autoimmune encephalomyelitis (EAE), there is a robust upregulation of IL15R $\alpha$, the specific receptor for IL15, in different CNS regions. Concurrently, these EAE mice show decreased permeation of blood-borne IL15 to the brain and spinal cord (Hsuchou et al., 2009b). By contrast, mice with generalized sickness behavior after challenge with the bacterial endotoxin lipopolysaccharide (LPS) show activation of the blood-to-CNS transport of IL15 (Pan et al., 2008b). These results suggest a role of IL15 in neuroinflammation. However, it is not yet clear how IL15 facilitates or limits neuroinflammation.

In this study, we used multidisciplinary approaches to determine the functions of IL15 and IL15R $\alpha$ in the normal brain. By behavioral measurement and mass spectrometric analysis of neu- 
rotransmitters, we confirmed the hypothesis that GABA is a major neurotransmitter affected by deletion of IL15R $\alpha$. This was further supported by results from immunohistochemistry (IHC) and Western blotting (WB) of the GABA-synthesizing enzyme glutamic acid decarboxylase (GAD)-67 and -65, and electron microscopic analysis of synapses. The direct actions of IL15 are shown by synaptosomal assays and by IL15 treatment of cultured neurons. Overall, IL15R $\alpha$ signaling is essential to maintain hippocampal GABA concentrations, at least partially involving reduced GABA turnover, and results in facilitation of memory consolidation. We speculate, therefore, that an upregulated IL15 system during neuroinflammation and autoimmunity may be beneficial to combat sickness behavior and memory deficits in experimental animals and human beings.

\section{Materials and Methods}

Behavioral studies

All studies followed a protocol approved by the Institutional Animal Care and Use Committee. Mice were purchased from The Jackson Laboratory and housed in the animal care facility for at least 2 weeks before

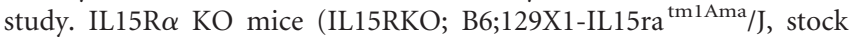
number 003723) were studied at 3-3.5 months old along with their matched controls (B6.129SF2/J, stock number 101045).

Stone T-maze. The 14-unit Stone T-maze is a combination of a scaleddown 14-unit maze and water-based T-maze established for testing hippocampal-dependent working memory (Del Arco et al., 2007; Locchi et al., 2007). It is modified from a version previously used in rats (Ingram, 1988). Rather than shock, escape from water is the motivation (Pistell and Ingram, 2010). The mice were rewarded for successful task performance by escaping from water into a dark and dry goal box elevated above the water level. The maze was placed in a water-filled tray at a level allowing the mouse to keep its head above the water while still touching the floor. The ceiling of the maze was low enough to prevent the mice from rearing out of the water $(1.5 \mathrm{~cm}$ between top of water and ceiling of maze). After pretraining in a straight runway where the mice were required to reach the goal box in $15 \mathrm{~s}$ or less in $13 / 15$ trials on day 1 , acquisition was assessed the following day by administration of 15 trials, with an $8-10 \mathrm{~min}$ intertrial interval. One week after acquisition, mice were returned to the maze to assess retention in 5 trials. The goal box was not visible from the runway, and the mice needed to express a clear directional preference before the goal box was visible. The primary dependent measures included errors and running time.

Fear conditioning test. As illustrated in Figure $2 \mathrm{~A}$, the mice were evaluated in an automated video fear conditioning system (Med Associates). Fear conditioning on day 1 consisted of 5 min of acclimation, followed by five stimuli of a $30 \mathrm{~s}$ tone $(85 \mathrm{~dB}, 4 \mathrm{kHz})$ that coterminated with a shock $(0.5 \mathrm{~mA} \times 1 \mathrm{~s})$. On day 2 , the mice were returned to the same chambers where no stimuli were applied. The activity level (percentage freezing) measured in $30 \mathrm{~s}$ intervals reflects contextual fear. On day 3 , the mice were returned to the chambers that had been modified. A flat floor overlay the usual grid, an insert modified the chamber dimensions, and an acetic acid odor was used to reinforce a novel environment. After habituation of the mice within the chambers for $5 \mathrm{~min}$, a continuous tone $(85 \mathrm{~dB}, 4 \mathrm{kHz})$ was applied for $5 \mathrm{~min}$. The percentage of freezing was recorded.

Liquid chromatography-tandem mass spectrometry analysis The hippocampi of each mouse were dissected, weighed, snap frozen in liquid nitrogen, and stored in $-80^{\circ} \mathrm{C}$. The samples were shipped on dry ice for mass spectrometric assay. After addition of refrigerated $5 \mathrm{~m}$ ammonium acetate ( $9 \mu$ l of buffer for each $1 \mathrm{mg}$ of brain tissue), brain tissue was homogenized by sonication while the sample tube was submerged in an ice bath. A $200 \mu \mathrm{l}$ aliquot of the homogenate was transferred into a tube, vortexed, and centrifuged. Twenty microliters of $20 \mu \mathrm{M}$ DOPACd5, GABA-d6, 5-HIAA-d5, NA-d6, dopamine-d4, and 5-HT-d4 were spiked as internal standards. The supernatants of the samples and the internal standards were injected onto a Primesep 200 column $(5 \mu \mathrm{m}$, $2.1 \times 50 \mathrm{~mm}$ ) (SIELC Technologies), and eluted with a methanol gradient. The mobile phase was increased over $9.5 \mathrm{~min}$ from $0.2 \%$ formic
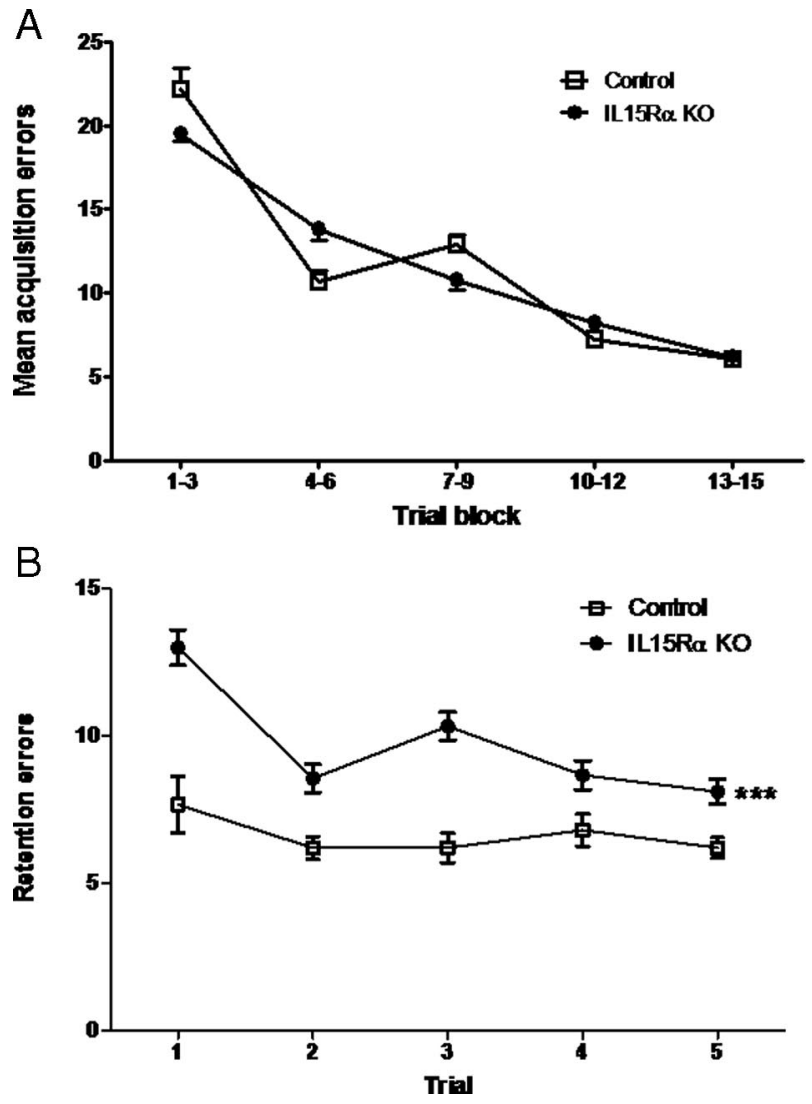

Figure 1. Learning and memory in the IL $15 \mathrm{R} \alpha \mathrm{K} 0$ and control mice were determined with a Stone T-maze ( $n=9 /$ group). $A$, Acquisition errors shown as means of three trial blocks were not different between the IL $15 R \alpha$ KO and control mice. $\boldsymbol{B}$, Retention errors were significantly higher in the $\mathrm{KO}$ mice when the mice were tested 1 week after the initial trial. ${ }^{* * *} p<0.005$.

acid/20 mm ammonium acetate in water to $0.2 \%$ formic acid $/ 20 \mathrm{~mm}$ ammonium acetate in methanol at a flow rate of $250 \mu \mathrm{l} / \mathrm{min}$. The fractions were detected by multiple reaction monitoring with an electrospray interface, operating in negative ion mode for DOPAC and positive ion mode for all the other analytes. The run time was $9.5 \mathrm{~min}$. The analytes were quantified against calibration curves with a concentration range of 0.2 to $500 \mu \mathrm{M}$ for GABA, and 0.02 to $50 \mu \mathrm{M}$ for other neurotransmitters.

\section{Immunohistochemistry}

The immunostaining procedure for GAD-67 and IL15R $\alpha$ in coronal sections of mouse brain including dorsal hippocampus was described previously (Pan et al., 2008a; Hsuchou et al., 2009a), with the additional use of a mouse-on-mouse blocking kit (Vector Laboratories) to reduce nonspecific staining in relation to the monoclonal antibody. Free-floating cryosections of $20 \mu \mathrm{m}$ thickness were used. A mouse monoclonal antibody against GAD-67 was used at 1:500 dilution (Millipore cat MAB5406, clone 1G10.2). The negative control with the absence of primary antibody did not show immunofluorescence. The GAD-65 antibody (Abcam) was not suitable for IHC because of diffuse nonspecific staining and therefore was only used for WB. The IL15R $\alpha$ antibody was a goat polyclonal antibody against the N-terminal extracellular domain of the mouse receptor (N19, sc-1524, Santa Cruz Biotechnologies), and was used at 1:100 dilution. The specificity was shown by the lack of signal in the IL15RKO mice and in normal mouse sections with omission of primary antibody or prior overnight incubation with the blocking peptide (sc-1524p). For doublelabeling studies with Alexa594-conjugated donkey anti-goat and Alexa488-conjugated donkey anti-mouse primary antibodies, potential cross-reaction between the irrelevant antibodies was also eliminated by use of additional negative controls with single staining. The images from structurally similar sections of the control and IL $15 \mathrm{R} \alpha \mathrm{KO}$ mice were acquired with identical parameters under an Olympus FV1000 confocal 
A
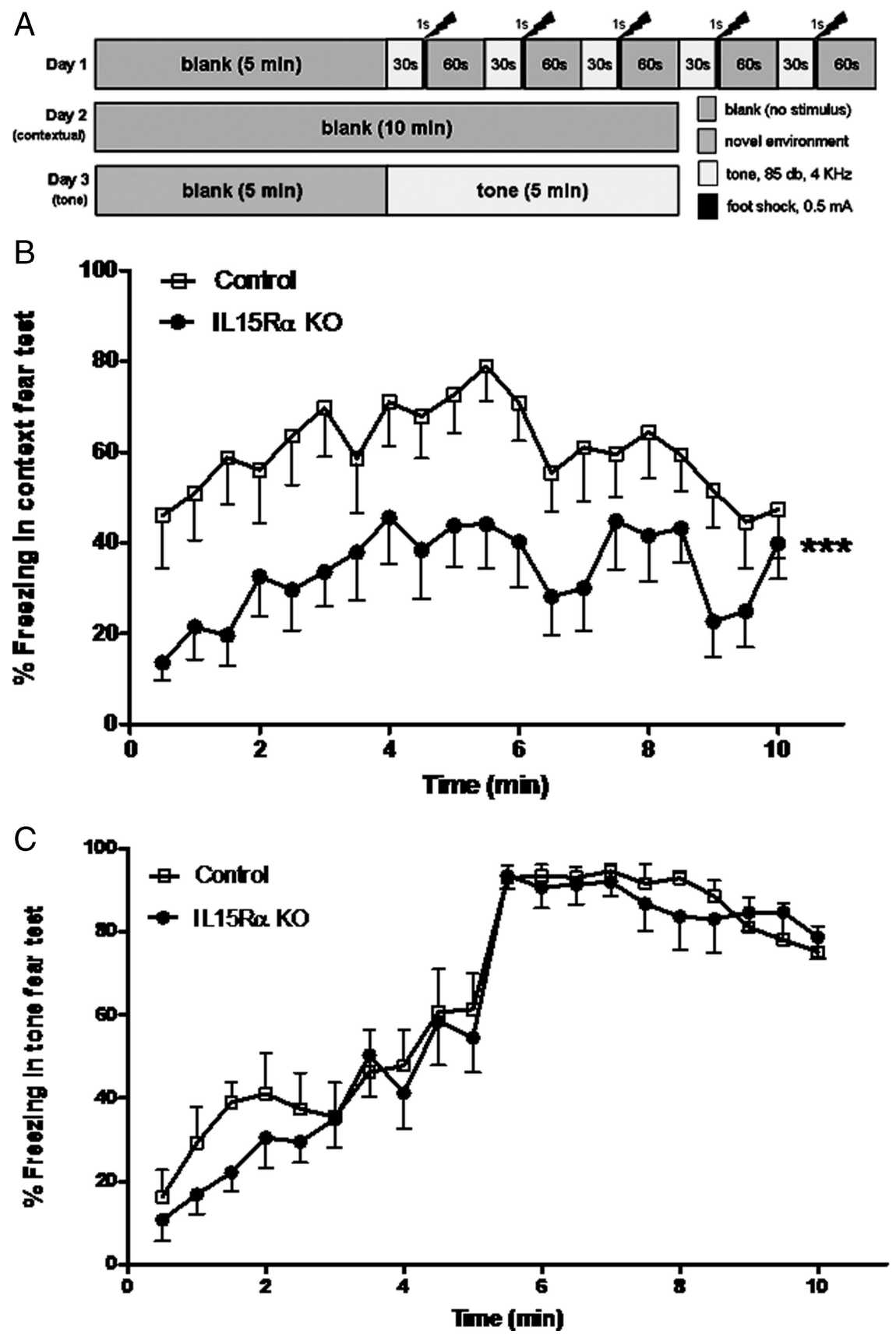

Figure 2. Fear conditioning test of the IL $15 \mathrm{R} \alpha \mathrm{K} 0$ and control mice ( $n=8 /$ group). $\boldsymbol{A}$, Schematic presentation of the test paradigm. $\boldsymbol{B}$, In the contextual test (day 2), the IL15R $\alpha$ KO mice had a lower percentage of freezing $\left({ }^{* * *} p<0.005\right)$. The total amount of freezing throughout the contextual test period of $10 \mathrm{~min}$ also showed a significant reduction in the IL $15 \mathrm{R} \alpha \mathrm{KO}$ mice $(p<0.05)$. $\boldsymbol{C}$, In the tone test (day 3 ), there was no difference in the freezing response to auditory conditioning stimulus between the groups.

microscope. Three independent sets of mice were used to quantify the region-specific alterations of GAD-67 staining ( $n=3$ /group). The cornu ammonis CA1, CA2, and CA3 regions of the hippocampus were subdivided into stratum oriens, pyramidal layer, and stratum radiatum. The dentate gyrus was further divided into the following regions: lacunosum molecular layer (LMol), molecular cell layer (Mol), granular layer dentate gyrus ( $\mathrm{GDG})$, and polymorphic region of the dentate gyrus (PoDG). Since there are two types of GAD-67 immunoreactivity, we used two types of analyses. To determine the difference of GAD-67 $(+)$ cell bodies, we performed cell counts in these areas, and normalized the data within the region of interest $\left(\mu \mathrm{m}^{3}\right)$. To determine the difference of immunofluorescent intensity of the GAD-67 (+) fibers, we quantified the gray value by thresholding, and present the data as percentage of thresholded areas. Differences between the $\mathrm{KO}$ and wild types were determined by one-way ANOVA for each subregion.

\section{Western blotting and image analysis}

Bilateral hippocampus and cingulate gyrus were dissected from fresh brain samples of control and KO mice immediately after decapitation ( $n=5 /$ group). The tissue was extracted in protein lysis buffer containing protease inhibitor cocktail. The lysates were cleared by ultracentrifuge, and protein concentration was quantified by bicinchoninic acid assay (Pierce). Forty micrograms of protein were electrophoresed, transferred overnight to a nitrocellulose membrane, and blocked with nonfat dried milk as described previously (He et al., 2009). The proteins were probed with primary antibodies against GAD-65, GAD- 67 , and the housekeeping gene $\beta$-actin as a loading control. This was followed by horseradish peroxide-conjugated secondary antibodies (GE Healthcare) in PBS containing $0.1 \%$ Tween 20 and $0.5 \%$ milk. The signals were developed with enhanced chemiluminescence-plus Western blotting detection reagents (GE Healthcare). The signal intensity was quantified by use of $\mathrm{NIH}$ ImageJ software, and expressed as GAD-65/ $\beta$-actin and GAD-67/ $\beta$-actin ratios.

\section{Electron microscopy}

Control and $\mathrm{KO}$ mice were anesthetized, perfused intracardially with $1 \%$ paraformaldehyde (PFA) and $2 \%$ glutaraldehyde (GA). The brain was postfixed in $0.5 \%$ PFA and $2.5 \%$ GA at $4^{\circ} \mathrm{C}$ as described previously (Pan et al., 2007; Wang et al., 2008). Coronal sections of $200 \mu \mathrm{m}$ thickness were obtained with a vibratome. The sections were completely immersed in PBS during processing. Rectangular tissue blocks were obtained in the CA1/DG, CA2/CA3 regions of the hippocampus, retrosplenial cingulate gyrus adjacent to the interhemispheric fissure, the ventromedial hypothalamus with partial inclusion of the arcuate nucleus and median eminence of the hypothalamus, and the basolateral amygdala. The tissue blocks were carefully trimmed, with the goal of maintaining exactly the same orientation and region encompassed between the control and $\mathrm{KO}$ groups. The blocks were further postfixed in $1 \%$ osmium tetroxide in sodium cacodylate buffer, dehydrated in gradient ethanol, exchanged with propylene oxide, and embedded in LR White resin (Electron Microscopy Sciences). Ultrathin sections of $80 \mathrm{~nm}$ thickness were collected onto 200 mesh copper grids and stained with uranyl acetate and lead citrate. For each region, five sets of images were captured from each mouse ( $n=2$ /group) to determine potential ultrastructural changes. Images were captured randomly by an experimenter blinded to treatment, and the synapses were counted by another experimenter who was also blinded to the groups. The axosomatic, axodendritic, and dendrodendritic synapses were all measured without distinction of subtypes.

\section{${ }^{3} \mathrm{H}-\mathrm{GABA}$ uptake by H19-7 and GT1-7 neuronal cells}

The H19-7 cell line of hippocampal origin and GT1-7 cell line of hypothalamic origin were studied independently. Confluent cells grown on polylysine-coated 24 -well plates ( $n=5$ /group) were pretreated with 0,1 , 
10 , or $100 \mathrm{ng} / \mathrm{ml} \mathrm{IL15} \mathrm{(PeproTech)} \mathrm{for} 1 \mathrm{~h}$ at $37^{\circ} \mathrm{C}$. The 0 time was the PBS control without the addition of IL15. The cells were then incubated with ${ }^{3} \mathrm{H}$-GABA $(700,000 \mathrm{cpm} / \mathrm{ml})$ for $20 \mathrm{~min}$ in the presence of the GABA transaminase inhibitor aminooxyacetic acid (AOAA). This was followed by rapid removal of unbound tracer with two PBS washes and collection of cell-associated ${ }^{3} \mathrm{H}-\mathrm{GABA}$ after cell lysis in $0.2 \mathrm{~N} \mathrm{NaOH}$ with $1 \%$ Triton $\mathrm{X}-100$. The stock solution, unbound, and cellular uptake fractions were mixed with scintillation cocktail and measured in a Beckman $\beta$-counter. The percentage of ${ }^{3} \mathrm{H}$-GABA uptake was calculated and the differences among the treatment groups were determined by one-way ANOVA for each type of cell.

To eliminate the possibility of toxicity from the IL15 treatment, cellular ATP production was determined with a ViaLight plus luminescence detection kit (Lonza Rockland). Four groups of GT1-7 cells $\left(5 \times 10^{4} /\right.$ well) were seeded onto a 96-well plate and cultured overnight $(n=$ 5/group). The cells were treated with IL15 at doses of $0,1,10$, and 100 $\mathrm{ng} / \mathrm{ml}$ for $6 \mathrm{~h}$, the 0 dose group being the vehicle control. After sequential addition of cell lysis agent and ATP production monitoring agent to the cells, the intensity of luminescence was measured with a $20 / 20^{\mathrm{n}}$ tube luminometer (Turner Biosystems). Since the concentration of ATP produced by the cells showed linear correlation with the conversion of luciferin to oxyluciferin in the presence of oxygen, the light emission and luminescent intensity reflect cellular activity level.

\section{${ }^{3} H$-GABA uptake by synaptosomes}

Two groups of synaptosomes from 3-month-old male C57 mice received IL15 and PBS treatment ( $n=6$ mice/group). Synaptosomes were prepared from the cerebral cortex of mice following a standard protocol (Sutch et al., 1999). In brief, the cortex (including hippocampi) from each mouse was homogenized separately in sucrose buffer. The supernatant was cleared by centrifugation at $1000 \times g$ for $10 \mathrm{~min}$, further centrifuged at 25,000 $\times g$ for $30 \mathrm{~min}$, and resuspended in Krebs-HEPES buffer. One forebrain yielded $\sim 8 \mathrm{mg}$ of synaptosomes. After measurement of protein concentrations by bicinchoninic acid assay (Pierce), the synaptosomes from each mouse were aliquoted to 96-well plates $(1 \mu \mathrm{g} / 100$ $\mu \mathrm{l} /$ well), with triplicated wells for each sample and parallel wells with inclusion of 1000-fold excess of unlabeled GABA (Sigma) to determine the nonspecific uptake. AOAA was included at a final concentration of 10 $\mu \mathrm{M}$ to all the wells. This reduces the degradation of internalized ${ }^{3} \mathrm{H}$ GABA that might be released extracellularly and interfere with estimation of the percentage of GABA reuptake. The synaptosomes were pretreated with IL15 $(100 \mathrm{ng} / \mathrm{ml})$ or PBS vehicle for $1 \mathrm{~h}(n=6$ mice/ group). ${ }^{3} \mathrm{H}$-GABA ( $2.5 \mathrm{~nm}, 87 \mathrm{Ci} / \mathrm{mmol}$, from GE Healthcare) was added to the synaptosomes with IL15 or PBS cotreatment. Twenty minutes later, the free and synaptosomal ${ }^{3} \mathrm{H}$-GABA were separated by rapid filtration onto glass fiber type $B$ filters. The filters were thoroughly washed with PBS, completely dried, and mixed with Betaplate scintillation cocktail (PerkinElmer). The radioactivity was measured in a 1450 MicroBeta TriLux Microplate Scintillation and Luminescence Counter (PerkinElmer).

\section{Statistical analysis}

Group means are presented with SEs and plotted by use of Prism GraphPad software. Two-way repeated-measures ANOVA was performed for behavioral studies. The effects of strain and trials and their interactions were determined. One-way ANOVA was performed for biochemical assays and imaging analysis as specified in the Results section.

\section{Results}

\section{IL15RKO mice show decreased learning and memory in the} T-maze test

In the Stone T-maze test appropriate to evaluate learning and memory in mice (Pistell and Ingram, 2010), two groups of 3 -month-old mice were studied ( $n=9 /$ group). The IL15RKO and control groups showed no difference in the errors made during memory acquisition. In Figure $1 A$, data from 15 trials are presented in five blocks of three consecutive trials. There was no difference between the $\mathrm{KO}$ and wild-type mice, although there

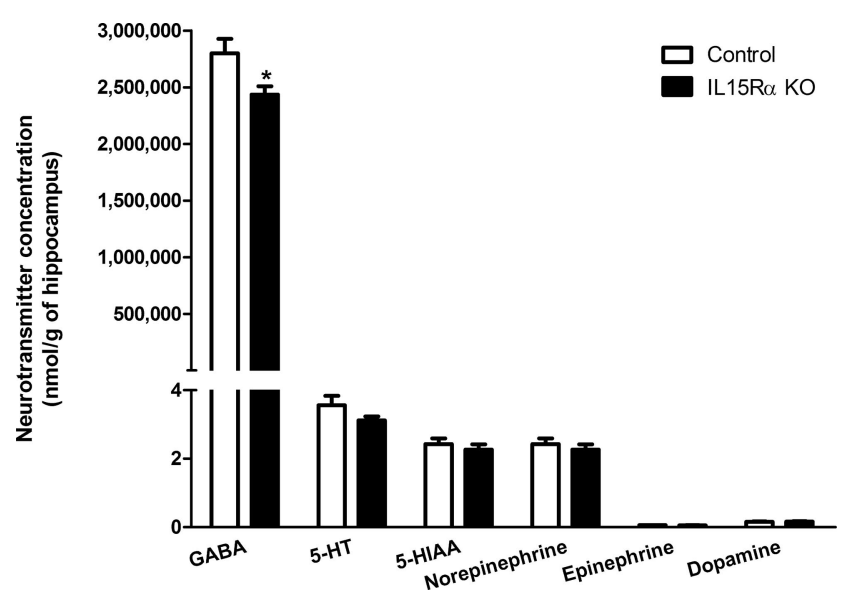

Figure 3. Mass spectroscopic measurement in hippocampal homogenates ( $n=5 /$ group). GABA concentrations in the hippocampus were lower in the K0 group $(2.435 \pm 0.073 \mu \mathrm{mol} / \mathrm{g})$ than the controls $(2.800 \pm 0.127 \mu \mathrm{mol} / \mathrm{g})\left({ }^{*} p<0.05\right)$. All other neurotransmitters measured did not show significant changes. In the serotonin system, the control group had a 5 -HT concentration of $3.564 \pm 0.273 \mathrm{nmol} / \mathrm{g}$ and $5-H I A A$ of $2.426 \pm 0.165 \mathrm{nmol} / \mathrm{g}$. The $\mathrm{KO}$ group had a 5 -HT concentration of $3.120 \pm 0.112 \mathrm{nmol} / \mathrm{g}$ and $5-$ HIAA of $2.269 \pm 0.154 \mathrm{nmol} / \mathrm{g}$. Both values and the 5-HT/5-HIAA ratio did not show significant changes. The norepinephrine, epinephrine, and dopamine levels were all low and did not show a significant change.

was a significant trial effect in that mice showed improvement in performance after the first two blocks of trials. Figure $1 B$ shows memory retention a week after the initial trial. There was a significant effect of the strain $(p<0.005)$. The KO mice had a rapid deterioration with more errors in the first three blocks of trials. There was also a significant interaction between the trials and strain. Overall, IL15R $\alpha$ deficiency led to specific deficits in memory retention, while acquisition remained intact.

\section{IL15RKO mice show deficits in contextual memory in the fear conditioning test}

Fear conditioning was evaluated in the same groups of mice over three consecutive days. The key elements in the test schedule are shown in Figure 2 A. On day 1, all mice showed a similar reaction to footshock. Twenty-four hours later, the mice were returned to the same testing chambers, although no tone or footshock was applied. The KO mice showed a lower percentage of freezing. This is shown by repeated-measures ANOVA for all measures taken at $30 \mathrm{~s}$ intervals $(p<0.005)$ (Fig. $2 B)$. The accumulated freezing events were $60.38 \pm 7.36 \%$ in the control and $33.78 \pm$ $4.83 \%$ in the $\mathrm{KO}$ group. The difference was also statistically significant $(p<0.05)$. On day 3 , the mice returned to a novel environment. Neither group of mice froze to the novel context during the first 10 blocks of recording $(0-5 \mathrm{~min})$. In the second half of the recording $(5 \mathrm{~min})$, a continuous tone was applied to better detect possible desensitization of the mice. The tone conditioning stimulus immediately increased freezing in both groups. There was no difference in the percentage of freezing to tone (Fig. 2C). Thus, the IL15RKO mice had deficits in contextual memory but maintained their emotional memory without extinction.

\section{Effects of IL15R $\alpha$ deletion on GABA concentrations in the hippocampus}

GABA concentrations in hippocampal homogenates were analyzed with mass spectrometry by experimenters blinded to the treatment groups. The analytes were quantified against calibration curves with a concentration range of 0.2 to $500 \mu \mathrm{M}$ for 

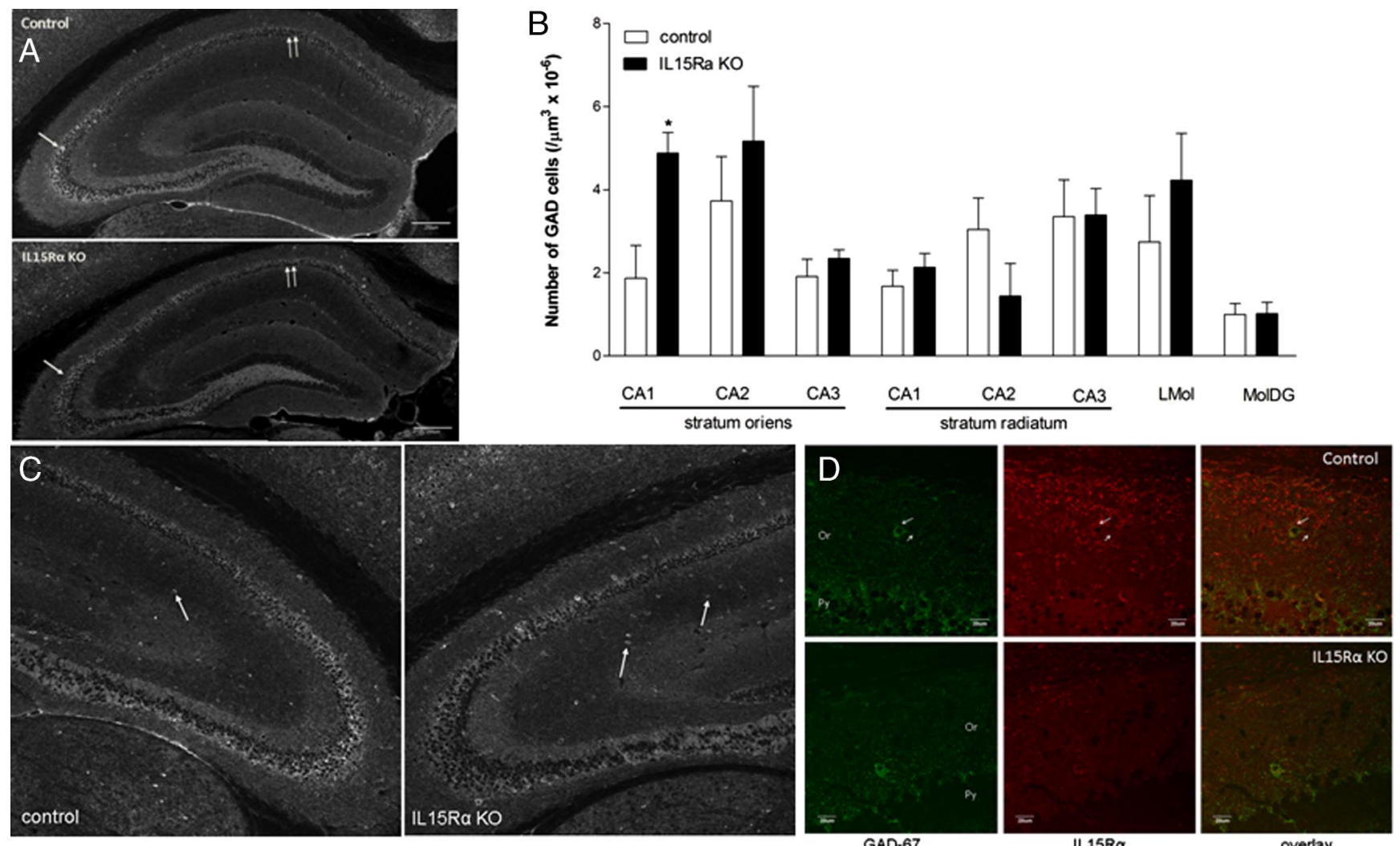

Figure 4. IHC revealed a region-specific distribution of GAD67 immunoreactivity that showed an increase in the number of interneurons in the stratum oriens of the CA1 region in the IL15R $\alpha$ KO mice. $n=3 /$ group. $A$, In the control mice, two types of GAD-67 immunostaining were seen. This includes the soma of interneurons dispersed in the dendritic layer, and synaptic terminals in the granular cell layers in CA and DG regions (arrows). In the $K 0$ mice, there seemed to be a subtle increase of the number of scattered immunopositive neurons but a reduction in the staining intensity of the synaptic terminals. $B$, Cell counts showed that the KO mice had significantly more GAD-67 (+) neurons only in the stratum oriens of the CA1 region. ${ }^{*} p<0.05$. $C$, Representative images showing increased number of GAD-67 (+) interneurons in a K0 mouse (right panel) in comparison with the control mouse (left panel). D, Colocalization of IL15R $\alpha$ with GAD-67 in the control mice was seen in some interneurons and cellular processes of the stratum oriens of the CA1 region (Or, arrows), and to a lesser extent in the pyramidal cell layer (Pr). The immunoreactivity of IL15R $\alpha$ was absent in the Or region of the KO mouse, but the staining for GAD-67 persisted.

GABA. The basal GABA concentration in hippocampal homogenates from wild-type mice was $2.800 \pm 0.127 \mu \mathrm{mol} / \mathrm{g}(n=$ 5/group). The GABA concentration in the IL15RKO mice was $2.435 \pm 0.073 \mu \mathrm{mol} / \mathrm{g}(n=5 /$ group $)$. The decrease was significant $(p<0.05)$. The concentrations of other neurotransmitters analyzed were all 800-fold lower. Specifically, the levels of serotonin $(5-\mathrm{HT})$ were $3.564 \pm 0.273 \mathrm{nmol} / \mathrm{g}$ in the wild-type mice and $3.120 \pm 0.112 \mathrm{nmol} / \mathrm{g}$ in the $\mathrm{KO}$ group. The difference was not statistically significant. The major metabolite for 5-HT, 5-hydroxyindoleacetic acid (5-HIAA), also did not differ between the wild-type $(2.426 \pm 0.165 \mathrm{nmol} / \mathrm{g})$ and $\mathrm{KO}(2.269 \pm$ $0.154 \mathrm{nmol} / \mathrm{g}$ ) mice. Similarly, the 5-HT/5-HIAA ratio did not show a significant difference. Among the monoamines, the control group had a norepinephrine level of $2.426 \pm 0.164 \mathrm{nmol} / \mathrm{g}$, epinephrine level of $0.059 \pm 0.004 \mathrm{nmol} / \mathrm{g}$, and dopamine level of $0.155 \pm 0.013 \mathrm{nmol} / \mathrm{g}$. The $\mathrm{KO}$ mice had respective values of $2.269 \pm 0.154,0.053 \pm 0.005$, and $0.166 \pm 0.011 \mathrm{nmol} / \mathrm{g}$. There were no significant changes in these values (Fig. 3).

\section{Effects of IL15R $\alpha$ deletion on the expression and distribution of the GABA-synthesizing enzyme GAD-67}

GABA is synthesized from glutamate by GAD. There are two isoforms, GAD-67 and GAD-65, encoded by two different genes. We determined the expression of the major isoform GAD-67 by immunohistochemistry with a monoclonal antibody (Millipore, MAB5406, 1:1000). Confocal microscopy showed that there were two immunostaining patterns for GAD-67. The first type was present in synaptic processes, innervating the perisomatic domain of principal cell layers as previously described (Fukuda et al., 1998). This includes boutons in the stratum pyramidale of the cornu ammonis regions and the granular cell layer of the dentate gyrus. The second type of immunostaining was in the cytoplasm of interneurons in dendritic layers, including strata lacunosummoleculare, radiatum, and oriens of the hippocampus proper and the molecular layer of the DG. There was a regional difference in the changes of GAD-67-immunopositive cells in the $\mathrm{KO}$ mice (Fig. 4A). The fluorescence intensity of GAD-67 synapses in the CA1 and CA3 granular cells appeared to be reduced in the KO mice. However, quantification of fluorescent intensity after thresholding of mean gray values and measurement of each individual subregion of interest failed to show statistically significant changes. The visual difference was therefore probably related to variations in even slightly different layers of the hippocampus, but not caused by IL15R $\alpha$ deletion. Nonetheless, the number of GAD-67 $(+)$ cells was significantly higher $(p<0.05)$ in the stratum oriens of the CA1 region of the KO group (Fig. $4 B$ ). Figure $4 C$ shows representative images from one of the three sets of mice processed independently. The spatial relationship between GAD-67 and IL15R $\alpha$ immunoreactivity can be seen in Figure $4 D$. There was some colocalization of IL15R $\alpha$ and GAD-67 in the stratum oriens of the CA1 region, suggesting a role 
of IL15 signaling in synaptic activity. The specific staining of IL15R $\alpha$ was absent in the $\mathrm{KO}$ mice.

\section{Quantification of GAD-65 and -67 by WB}

Although the GAD-65 antibody was not appropriate for immunofluorescent staining, it showed adequate immunoreactivity in WB. In the hippocampal homogenate, there was a significant increase of GAD-65 signal in the KO group in comparison with the wild-type controls $(n=5 /$ group). By contrast, there was no significant change of GAD-65 signal in the cingulate gyrus between the two groups. In both regions, the signal of GAD-67 did not show significant changes (Fig. $5 A$ ). This was verified by densitometry analysis (Fig. 5B).

\section{Ultrastructure and the number of} synapses in the $\mathrm{KO}$ mice

The gross morphology, cellularity, and ultrastructure of the hippocampus did not show a striking difference between the wild-type and $\mathrm{KO}$ mice. Four brain regions were sampled. The choices of the regions were mainly based on their specific anatomical role in memory and emotion (hippocampus, amygdala, and retrosplenial region of the cingulate gyrus). The ventromedial hypothalamus was included as a control. In all regions, axosomatic, axodendritic, and dendrodendritic synapses remained intact. There was no statistically significant difference in the overall synaptic numbers. Figure 6 shows representative images in the DG/ $\mathrm{CA} 1$ region of the wild-type and $\mathrm{KO}$ groups.

\section{Dose-dependent effects of IL15 on ${ }^{3} \mathrm{H}-\mathrm{GABA}$ uptake by cultured neurons}

To determine whether IL15 shows direct effects on relatively homogeneous populations of cells, we performed ${ }^{3} \mathrm{H}$-GABA uptake assays. H19-7 cells of hippocampal neuronal origin and GT1-7 cells of hypothalamic neuronal origin were grown confluent in 24-well plates. After $1 \mathrm{~h}$ of pretreatment with $\operatorname{IL15}(0,1,10$, and $100 \mathrm{ng} / \mathrm{ml}$ ), the cells were incubated with ${ }^{3} \mathrm{H}-\mathrm{GABA}$ along with IL15 or PBS vehicle for another $20 \mathrm{~min}$. The percentage of ${ }^{3} \mathrm{H}$ GABA uptake showed a dose-dependent increase in response to IL15; it was significant only in the group receiving $100 \mathrm{ng} / \mathrm{ml}$ in both H19-7 (Fig. 7A) and GT1-7 cells (Fig. 7B). The test doses of IL15 did not reduce the amount of ATP production in GT1-7 cells even after $6 \mathrm{~h}$ of treatment (Fig. 7C). This indicates the absence of acute cell toxicity. The effective dose $(100 \mathrm{ng} / \mathrm{ml})$ was used for the synaptosomal studies below.

\section{Effects of acute IL15 treatment on ${ }^{3} \mathrm{H}$-GABA uptake} by synaptosomes

IL15 treatment ex vivo $(100 \mathrm{ng} / \mathrm{ml}$ with $1 \mathrm{~h}$ pretreatment and 20 min cotreatment) induced a significant reduction $(p<0.05)$ of
${ }^{3} \mathrm{H}-\mathrm{GABA}$ uptake by synaptosomes from wild-type mice. By contrast, synaptosome preparations from the KO mice showed an increase $(p<0.05)$ of ${ }^{3} \mathrm{H}-\mathrm{GABA}$ uptake (Fig. 8). The results suggest that IL15 had a direct effect on GABA turnover.

\section{Discussion}

In this study, we first used the IL15RKO mice to determine the effects of IL15R $\alpha$ deletion on emotional memory, hippocampal neurochemical changes, and synaptic uptake of GABA. The deficits of the IL15RKO mice in the T-maze and fear conditioning tests suggest that IL $15 \mathrm{R} \alpha$ signaling facilitates hippocampaldependent memory. Although there was no major ultrastructural change in the number of synapses and general morphology, there were region-specific alterations in the expression of the GABAsynthesizing enzyme GAD. Since the KO mice have several potentially confounding problems including compensatory changes after the embryonic absence of IL15R $\alpha$ in all cell types, we performed additional studies on neuronal cultures and synaptosomes from wild-type mice with intact IL $15 \mathrm{R} \alpha$. The biochemical evidence further indicates that GABA transmission is at least partially involved in the actions of IL15. 

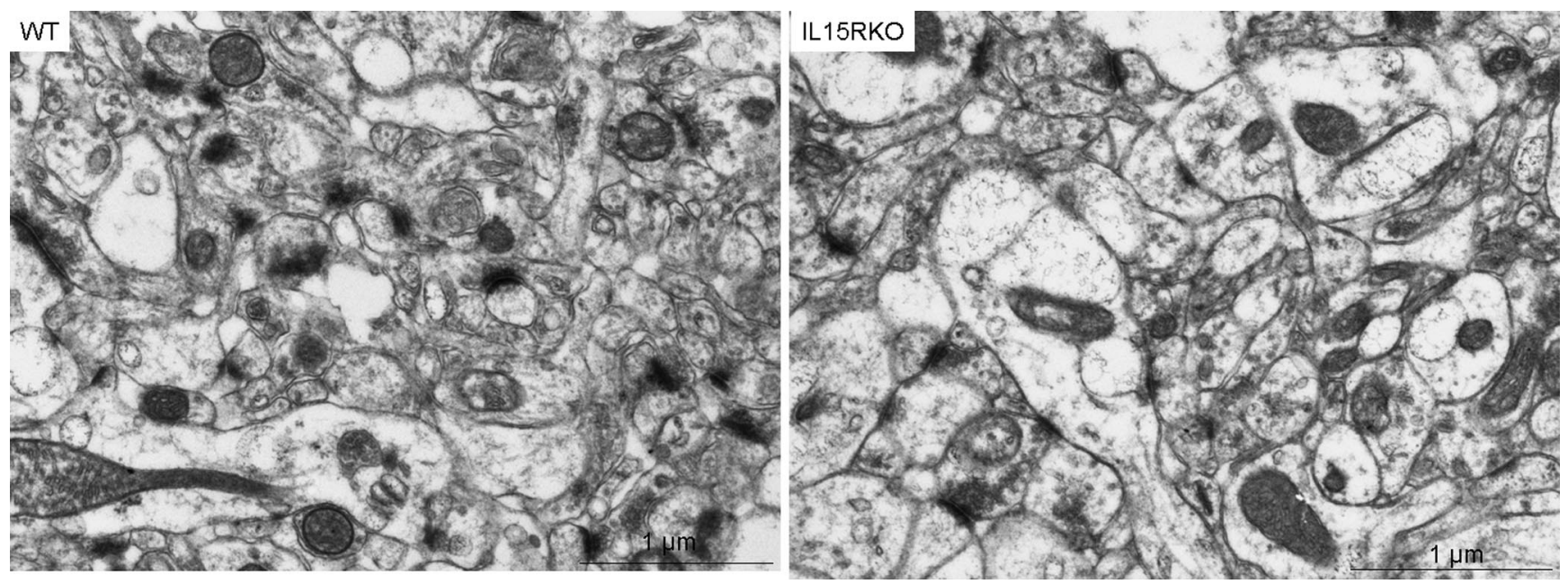

Figure 6. Electron microscopy showed that the cellular processes and synapses remained intact in the DG/CA1 region of the K0 mouse (right panel) in comparison with the control (left panel).

To evaluate spatial learning and memory, we first used a water escape-motivated mouse version of the Stone 14-unit T-maze (Pistell and Ingram, 2010). This avoids potential problems such as the unwillingness of mice to work for food or water rewards, their propensity to float or sink, and their reluctance to remain on the goal platform. The testing device is a combination of the scaled-down 14-unit maze (Ingram, 1988; Pistell and Ingram, 2010) and water-based T-maze established for testing hippocampal-dependent working memory (Del Arco et al., 2007; Locchi et al., 2007). The modified Stone 14-unit T-maze with a dry, dark target box as positive reinforcement for water escape has a more complex maze design. The position of the goal box in the 14-unit Stone T-maze was set to obscure any visual cues. It is not visible from the runway, and the mouse must express a clear left or right preference 14 times before reaching the goal box. The preference a mouse makes in the Stone T-maze is proposed to be dependent on an internally driven response algorithm, and is more of reference memory, or representational memory (Ingram, 1988). The IL15R $\alpha$ KO mice had no deficits in the acquisition tasks, but did worse in memory retention than the controls.

To confirm the role of IL15R $\alpha$ in hippocampal-dependent memory consolidation, we further determined the performance of these mice in Pavlovian fear conditioning. Classical fear conditioning is a well established learning model, with the amygdala and hippocampus as main structural substrates (LeDoux, 2000; Bergado-Acosta et al., 2008). The mice were exposed to tone (conditioned stimulus) and footshock (unconditioned stimulus), and tested for context-dependent memory and conditioned auditory fear. The IL15R $\alpha$ KO mice exhibited normal emotional memory but impaired contextual memory. Thus, the hippocampus appears to be one of the major structural components mediating the memory deficits of the IL $15 \mathrm{R} \alpha \mathrm{KO}$ mice.

It has been shown that hippocampal activity is required for early consolidation of fear conditioning with a short trace interval (Corcoran et al., 2005; Burman and Gewirtz, 2007; Ji and Maren, 2007). GABA is one of the major neurotransmitters involved in this process (Myers and Davis, 2002; Heldt et al., 2004; BergadoAcosta et al., 2008). Among the six neurotransmitters measured in this study, GABA is the main neurotransmitter that showed a significant decrease in the hippocampus of IL15R $\alpha$ KO mice. This contrasts with the lack of changes of the monoamines epinephrine, norepinephrine, and dopamine that were measured simultaneously by mass spectrometry, suggesting some specific- ity of IL15 in maintaining GABA concentrations. Serotonin, 5-HIAA, and the 5-HT/5-HIAA ratio also did not show a significant change. We did not measure the concentrations of glutamate or acetylcholine; it is possible that they and many neuropeptides and lipid signals might also be involved.

The reduced GABA concentration in the hippocampus may have resulted from decreased synthesis and/or accelerated turnover. The actions of GABA downstream to $\mathrm{GABA}_{\mathrm{A}}$ and $\mathrm{GABA}_{\mathrm{B}}$ receptor signaling may also change independently. We next measured the expression of the rate-limiting synthesizing enzymes. IHC data showed a regional difference in the normal distribution of GAD-67 that was present at high levels in sparsely located interneurons and at low levels in synapses innervating granular cells. Since GAD-67 may be synthesized in extrahippocampal sites and anterogradely transported along projection pathways, the reduction of extrahippocampal GAD-67 might explain part of the reduction of GABA concentration detected by mass spectrometry. Nonetheless, there was an increase in the number of GAD-67 cells without a change of fluorescent intensity. In WB analysis of hippocampal homogenates, the expression of GAD65 , the other isoform, was significantly increased. These two unexpected findings might be explained by adaptive changes of the IL15R $\alpha$ KO mice. In the absence of IL15R $\alpha$, the coreceptors in the trimeric complex may undergo regulatory alterations. IL2R $\beta$ was significantly decreased, but IL2R $\gamma$ was significantly increased (X. Wu, H. Hsuchou, A. J. Kastin, and W. Pan, unpublished observations). Opposite directions of change of IL15 receptor subtypes are also seen in cerebral microvessels and cultured endothelial cells in response to TNF (Pan et al., 2009). Both IL2R $\beta$ and IL $2 \mathrm{R} \gamma$ are shared by many cytokines in the large family of four- $\alpha$-helix bundle family of cytokines. The unopposed increase of IL2R $\gamma$ might have resulted in compensatory changes in the $\mathrm{KO}$ mice.

The GABA-synthesizing enzymes GAD-67 and GAD-65 may be colocalized in the same GABAergic neurons, although their distribution is not even (Fukuda et al., 1998). GAD-67 plays a more important role, since GAD-67 deletion is lethal, whereas GAD-65 KO mice are viable although they are susceptible to seizures (Asada et al., 1996). In the DG, CA1, and CA3 areas, there was a reduction in the number of neurons receiving GAD-67 (+) synapses, suggesting a corresponding decrease of inhibitory neurotransmission. Therefore, we further determined synaptic morphology by ultrastructural studies. Although the 

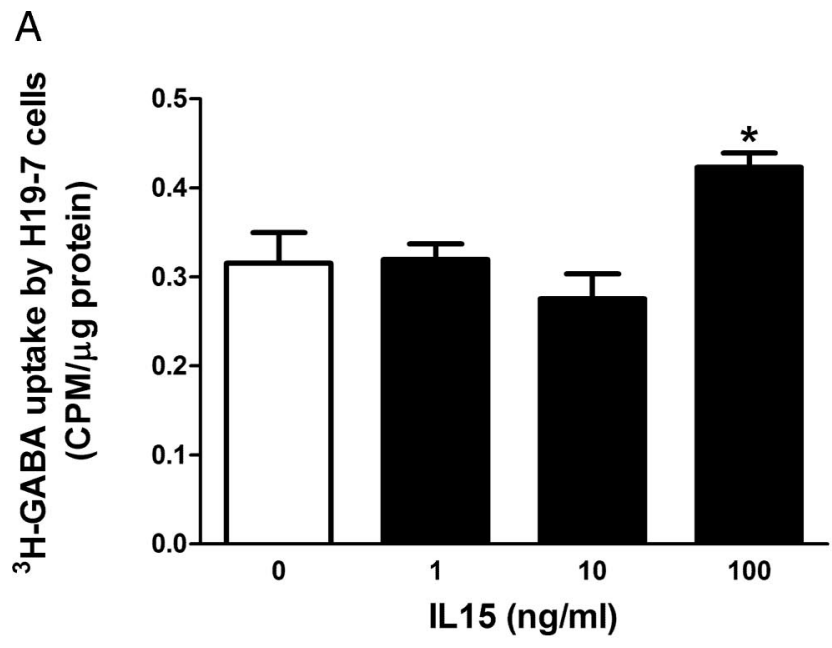

B
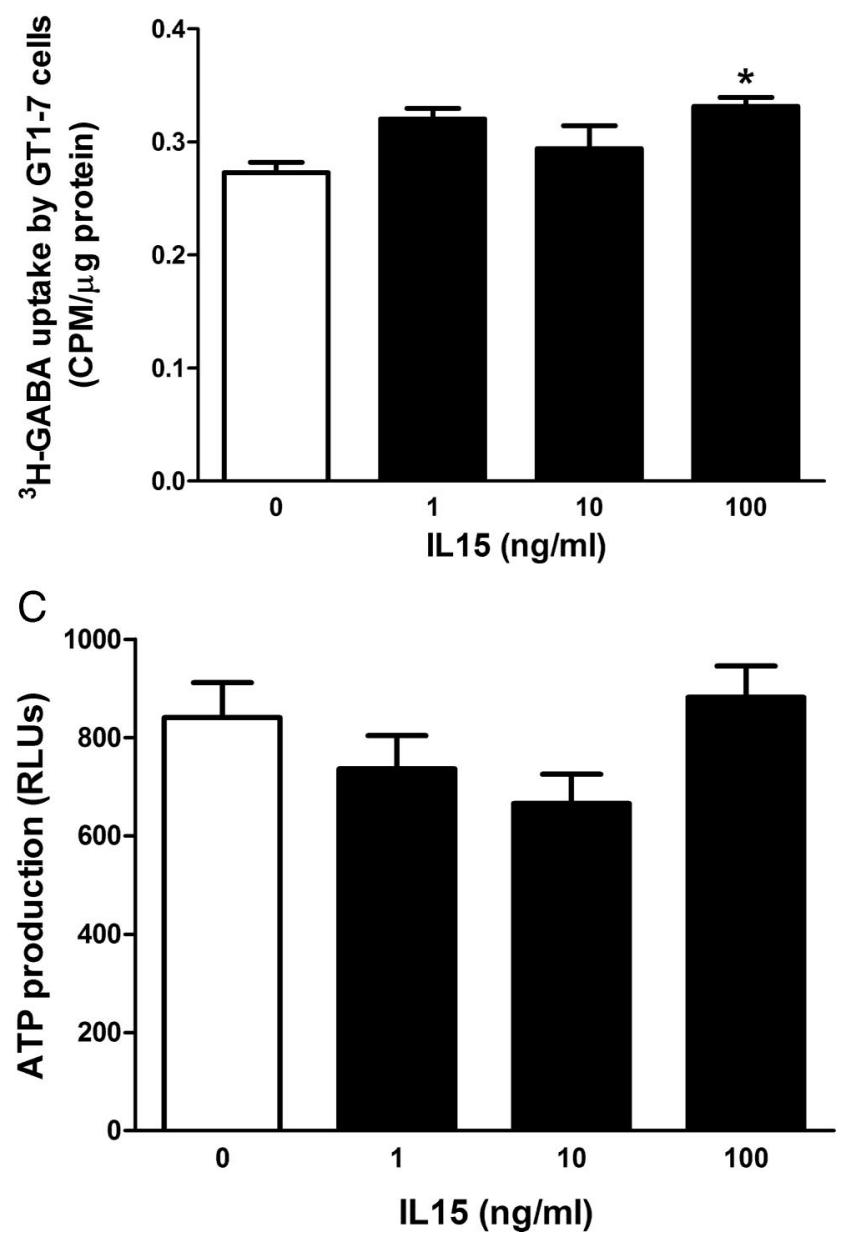

Figure 7. Dose-response study of the effects of IL 15 on ${ }^{3} \mathrm{H}$-GABA uptake by cultured neurons and assessment of cytotoxicity. $n=5 /$ group. ${ }^{*} p<0.05 . A, \mathrm{IL} 15$ pretreatment for $1 \mathrm{~h}$ followed by cotreatment for 20 min induced an increase of ${ }^{3} \mathrm{H}-$ GABA uptake by H19-7 cells only at $100 \mathrm{ng} / \mathrm{ml}$ but not lower doses. $\boldsymbol{B}$, With the same regimen, IL15 treatment increased the uptake of ${ }^{3} \mathrm{H}-\mathrm{GABA}$ by GT1-7 cells only at $100 \mathrm{ng} / \mathrm{ml}$. C, A longer treatment interval $(6 \mathrm{~h})$ of $\mathrm{LL} 15(1,10$, and $100 \mathrm{ng} / \mathrm{ml})$ did not suppress cellular ATP production in GT1-7 cells, indicating the lack of toxicity.

hippocampus of the KO mice might have a subtle decrease in the number of inhibitory and total synapses, the changes were not significant. It is possible that a greater sample size is necessary, and also visualization and counting of the synapses with high-

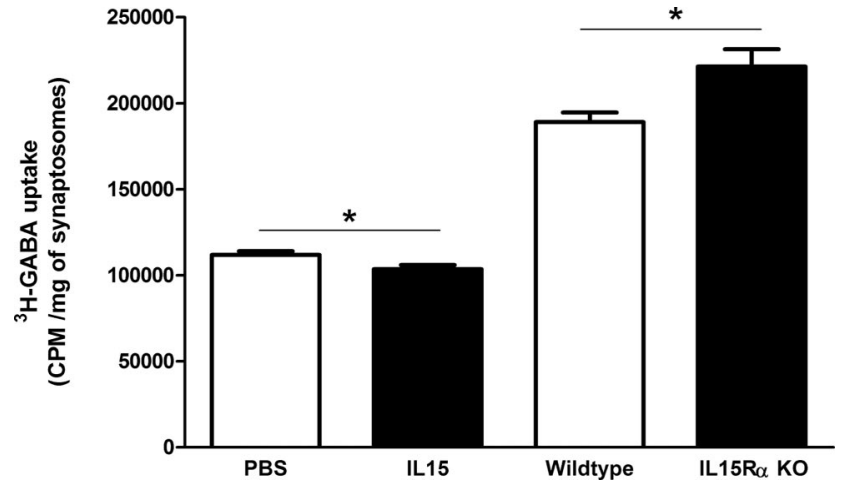

Figure 8. Role of IL15 in the synaptosomal uptake of ${ }^{3} \mathrm{H}-\mathrm{GABA}$ ( $n=6 /$ group). In the left panel, IL15 pretreatment for $1 \mathrm{~h}$ followed by cotreatment for $20 \mathrm{~min}$ decreased the uptake of ${ }^{3} \mathrm{H}-\mathrm{GABA}$ by synaptosomes from adult $\mathrm{B} 6$ mice. In the right panel, synaptosomal uptake of ${ }^{3} \mathrm{H}-\mathrm{GABA}$ was increased in the IL $15 \mathrm{R} \alpha \mathrm{KO}$ mice. ${ }^{*} p<0.05$.

magnification electron microscopic images may not be sufficient without immunolabeling of GABA or GAD in ultrathin sections. Regardless, the changes in synaptic structure do not seem to be a major mediator of the actions of IL15 on the hippocampus.

IL15R $\alpha$ was neuronally distributed in the granular cells of the hippocampus. It showed a remarkable colocalization with GAD67, and it was also present in GAD-67 (+) interneurons. Therefore, we next tested whether IL15 directly affects GAD expression in cultured neurons. However, preliminary data showed that IL15 did not acutely modulate GAD expression in H19-7 cells at 10 or $100 \mathrm{ng} / \mathrm{ml}$ for 30-180 $\mathrm{min}$ (X. Wu, R. S. Khan, A. J. Kastin, and W. Pan, unpublished observations). By contrast, IL15 was able to increase the uptake of ${ }^{3} \mathrm{H}$-GABA in both H19-7 hippocampal neurons and GT1-7 hypothalamic neurons in a dosedependent manner. The cellular studies were insufficient to indicate whether this represented a presynaptic reuptake mechanism or postsynaptic ligand endocytosis and receptor signaling. Nonetheless, the effective dose and lack of cellular toxicity in the ViaLight cell proliferation and ATP production assays provided a suitable dose for synaptosomal assays.

Although IL15R $\alpha$ KO mice showed distinctive behavioral and biochemical deficits, there are two limiting considerations. First, the embryonic deletion of IL15R $\alpha$ occurs not only in the CNS but also in immune cells and other organs. This might affect the interactions of peripheral systems with the CNS during development. Second, strain background may affect the outcome of behavioral studies (Bryant et al., 2008). This is the basis for the synaptosomal studies. In the preparations from wild-type mice, IL15 decreased ${ }^{3} \mathrm{H}$-GABA uptake. In those from the KO mice, ${ }^{3} \mathrm{H}-\mathrm{GABA}$ uptake was increased. These results are consistent with each other and support a role of IL15 in decreasing GABA turnover, presumably from the synaptic terminals. This is probably the best explanation for the decreased GABA concentration in the IL15R $\alpha$ KO mice, and suggests that synaptic GAD-67 contributes more to hippocampal GABA concentrations than that in sparsely distributed interneurons seen by IHC.

The novel role of the IL15 system in memory and GABA transmission contrasts with findings from IL1 studies. IL1 $\beta$ is known to affect the immune system and hippocampal-dependent memory consolidation (Rachal Pugh et al., 2001; Yirmiya et al., 2002). Contextual fear conditioning is impaired in rats after intraperitoneal injection of LPS, and this is prevented by subcutaneous injection of IL1ra that antagonizes IL1 $\beta$ (Pugh et al., 1998). Injection of IL1 $\beta$ into the dorsal hippocampus provides more direct 
evidence that it impairs the consolidation process in contextual fear conditioning for up to $24 \mathrm{~h}$ (Barrientos et al., 2002). By contrast, IL1RI-null mice show a decrease in anxiety-related behavior in the elevated plus maze, light-dark, and novelty-induced hypophagia tests. They also have more freezing in auditory and contextual fear conditioning tests. These are not caused by changes in locomotor activity or pain sensitivity (Koo and Duman, 2009). Furthermore, Yirmiya and colleagues showed a biphasic effect of intracerebroventricular IL1 $\beta$ on contextual memory, with a low dose (1 ng) improving and high dose (10 ng) decreasing it. Prenatal treatment with IL1ra also results in impaired fear conditioning performance in mice (Goshen et al., 2007). These results and the proposed inverted-U hypothesis are consistent with what we have reported after TNF treatment of EAE mice (Pan et al., 1996, 1997). By analogy, peripheral TNF enters the CNS by upregulated transport that may modulate neuroregeneration after spinal cord injury (Pan et al., 1999; Pan and Kastin, 2001), hippocampal trauma (Pan et al., 2003), and stroke (Pan et al., 2006). It is highly probable that a basal level of IL15R $\alpha$ signaling is needed for memory consolidation, although pathological levels of IL15 might inhibit memory consolidation.

In summary, IL $15 R \alpha$ is essential in maintaining hippocampal GABA transmission and preventing memory deficit in normal mice. In contrast to previous studies linking immunity and neurobehavior by use of disease models (inflammation in particular), the results show a prominent role of the basal functioning of the IL15 system in normal CNS activity, thus linking IL15 to mood and memory.

\section{References}

Asada H, Kawamura Y, Maruyama K, Kume H, Ding R, Ji FY, Kanbara N, Kuzume H, Sanbo M, Yagi T, Obata K (1996) Mice lacking the $65 \mathrm{kDa}$ isoform of glutamic acid decarboxylase (GAD65) maintain normal levels of GAD67 and GABA in their brains but are susceptible to seizures. Biochem Biophys Res Commun 229:891-895.

Barrientos RM, Higgins EA, Sprunger DB, Watkins LR, Rudy JW, Maier SF (2002) Memory for context is impaired by a post context exposure injection of interleukin-1 beta into dorsal hippocampus. Behav Brain Res 134:291-298.

Beck RD Jr, Wasserfall C, Ha GK, Cushman JD, Huang Z, Atkinson MA, Petitto JM (2005) Changes in hippocampal IL-15, related cytokines, and neurogenesis in IL-2 deficient mice. Brain Res 1041:223-230.

Bergado-Acosta JR, Sangha S, Narayanan RT, Obata K, Pape HC, Stork O (2008) Critical role of the 65-kDa isoform of glutamic acid decarboxylase in consolidation and generalization of Pavlovian fear memory. Learn Mem 15:163-171.

Bryant CD, Zhang NN, Sokoloff G, Fanselow MS, Ennes HS, Palmer AA, McRoberts JA (2008) Behavioral differences among C57BL/6 substrains: implications for transgenic and knockout studies. J Neurogenet 22:315-331.

Budagian V, Bulanova E, Paus R, Bulfone-Paus S (2006) IL-15/IL-15 receptor biology: a guided tour through an expanding universe. Cytokine Growth Factor Rev 17:259-280.

Burman MA, Gewirtz JC (2007) Hippocampal activity, but not plasticity, is required for early consolidation of fear conditioning with a short trace interval. Eur J Neurosci 25:2483-2490.

Corcoran KA, Desmond TJ, Frey KA, Maren S (2005) Hippocampal inactivation disrupts the acquisition and contextual encoding of fear extinction. J Neurosci 25:8978-8987.

Del Arco A, Segovia G, Garrido P, de Blas M, Mora F (2007) Stress, prefrontal cortex and environmental enrichment: studies on dopamine and acetylcholine release and working memory performance in rats. Behav Brain Res 176:267-273.

Fukuda T, Aika Y, Heizmann CW, Kosaka T (1998) GABAergic axon terminals at perisomatic and dendritic inhibitory sites show different immunoreactivities against two GAD isoforms, GAD67 and GAD65, in the mouse hippocampus: a digitized quantitative analysis. J Comp Neurol 395:177-194.
Goshen I, Kreisel T, Ounallah-Saad H, Renbaum P, Zalzstein Y, Ben-Hur T, Levy-Lahad E, Yirmiya R (2007) A dual role for interleukin-1 in hippocampal-dependent memory processes. Psychoneuroendocrinology 32:1106-1115.

Hanisch UK, Lyons SA, Prinz M, Nolte C, Weber JR, Kettenmann H, Kirchhoff F (1997) Mouse brain microglia express interleukin-15 and its multimeric receptor complex functionally coupled to Janus kinase activity. J Biol Chem 272:28853-28860.

He Y, Kastin AJ, Hsuchou H, Pan W (2009) The Cdk5/p35 kinases modulate leptin-induced STAT3 signaling. J Mol Neurosci 39:49-58.

Heldt SA, Green A, Ressler KJ (2004) Prepulse inhibition deficits in GAD65 knockout mice and the effect of antipsychotic treatment. Neuropsychopharmacology 29:1610-1619.

Hsuchou H, He Y, Kastin AJ, Tu H, Markadakis EN, Rogers RC, Fossier PB, Pan W (2009a) Obesity induces functional astrocytic leptin receptors in hypothalamus. Brain 132:889-902.

Hsuchou H, Pan W, Wu X, Kastin AJ (2009b) Cessation of blood-to-brain influx of interleukin-15 during development of EAE. J Cereb Blood Flow Metab 29:1568-1578.

Ingram DK (1988) Complex maze learning in rodents as a model of agerelated memory impairment. Neurobiol Aging 9:475-485.

Ji J, Maren S (2007) Hippocampal involvement in contextual modulation of fear extinction. Hippocampus 17:749-758.

Kobayashi H, Carrasquillo JA, Paik CH, Waldmann TA, Tagaya Y (2000) Differences of biodistribution, pharmacokinetics, and tumor targeting between interleukins 2 and 15. Cancer Res 60:3577-3583.

Koo JW, Duman RS (2009) Interleukin-1 receptor null mutant mice show decreased anxiety-like behavior and enhanced fear memory. Neurosci Lett 456:39-43.

Kubota T, Brown RA, Fang J, Krueger JM (2001) Interleukin-15 and interleukin-2 enhance non-REM sleep in rabbits. Am J Physiol Regul Integr Comp Physiol 281:R1004-R1012.

LeDoux JE (2000) Emotion circuits in the brain. Annu Rev Neurosci 23:155-184.

Lee YB, Satoh J, Walker DG, Kim SU (1996) Interleukin-15 gene expression in human astrocytes and microglia in culture. Neuroreport 7:1062-1066.

Locchi F, Dall'Olio R, Gandolfi O, Rimondini R (2007) Water T-maze, an improved method to assess spatial working memory in rats: pharmacological validation. Neurosci Lett 422:213-216.

Lodolce JP, Boone DL, Chai S, Swain RE, Dassopoulos T, Trettin S, Ma A (1998) IL-15 receptor maintains lymphoid homeostasis by supporting lymphocyte homing and proliferation. Immunity 9:669-676.

Maślińska D (2001) The cytokine network and interleukin-15 (IL-15) in brain development. Folia Neuropathol 39:43-47.

McInnes IB, Leung BP, Sturrock RD, Field M, Liew FY (1997) Interleukin-15 mediates $T$ cell-dependent regulation of tumor necrosis factor-alpha production in rheumatoid arthritis. Nat Med 3:189-195.

Myers KM, Davis M (2002) Behavioral and neural analysis of extinction. Neuron 36:567-584.

Pan W, Kastin AJ (2001) Upregulation of the transport system for TNF $\alpha$ at the blood-brain barrier. Arch Physiol Biochem 109:350-353.

Pan W, Banks WA, Kennedy MK, Gutierrez EG, Kastin AJ (1996) Differential permeability of the BBB in acute EAE: enhanced transport of TNF- $\alpha$. Am J Physiol 271:E636-E642.

Pan W, Zadina JE, Harlan RE, Weber JT, Banks WA, Kastin AJ (1997) Tumor necrosis factor $\alpha$ : a neuromodulator in the CNS. Neurosci Biobehav Rev 21:603-613.

Pan W, Kastin AJ, Bell RL, Olson RD (1999) Upregulation of tumor necrosis factor $\alpha$ transport across the blood-brain barrier after acute compressive spinal cord injury. J Neurosci 19:3649-3655.

Pan W, Kastin AJ, Rigai T, McLay R, Pick CG (2003) Increased hippocampal uptake of TNF $\alpha$ and behavioral changes in mice. Exp Brain Res 149:195-199.

Pan W, Ding Y, Yu Y, Ohtaki H, Nakamachi T, Kastin AJ (2006) Stroke upregulates TNF alpha transport across the blood-brain barrier. Exp Neurol 198:222-233.

Pan W, Kastin AJ, Daniel J, Yu C, Baryshnikova LM, von Bartheld CS (2007) TNF alpha trafficking in cerebral vascular endothelial cells. J Neuroimmunol 185:47-56.

Pan W, Hsuchou H, He Y, Sakharkar A, Cain C, Yu C, Kastin AJ (2008a) Astrocyte leptin receptor (ObR) and leptin transport in adult-onset obese mice. Endocrinology 149:2798-2806. 
Pan W, Hsuchou H, Yu C, Kastin AJ (2008b) Permeation of blood-borne IL15 across the blood-brain barrier and the effect of LPS. J Neurochem 106:313-319.

Pan W, Yu C, Hsuchou H, Khan RS, Kastin AJ (2009) Cerebral microvascular IL15 is a novel mediator of TNF action. J Neurochem 111:819-827.

Pistell PJ, Ingram DK (2010) Development of a water escape-motivated version of the Stone T-maze for mice. Neuroscience 166:61-72.

Pugh CR, Kumagawa K, Fleshner M, Watkins LR, Maier SF, Rudy JW (1998) Selective effects of peripheral lipopolysaccharide administration on contextual and auditory-cue fear conditioning. Brain Behav Immun 12:212-229.

Rachal Pugh C, Fleshner M, Watkins LR, Maier SF, Rudy JW (2001) The immune system and memory consolidation: a role for the cytokine IL1beta. Neurosci Biobehav Rev 25:29-41.

Rentzos M, Cambouri C, Rombos A, Nikolaou C, Anagnostouli M, Tsoutsou
A, Dimitrakopoulos A, Triantafyllou N, Vassilopoulos D (2006) IL-15 is elevated in serum and cerebrospinal fluid of patients with multiple sclerosis. J Neurol Sci 241:25-29.

Satoh J, Kurohara K, Yukitake M, Kuroda Y (1998) Interleukin-15, a T-cell growth factor, is expressed in human neural cell lines and tissues. J Neurol Sci 155:170-177.

Sutch RJ, Davies CC, Bowery NG (1999) GABA release and uptake measured in crude synaptosomes from genetic absence epilepsy rats from Strasbourg (GAERS). Neurochem Int 34:415-425.

Wang QP, Guan JL, Pan W, Kastin AJ, Shioda S (2008) A diffusion barrier between the area postrema and nucleus tractus solitarius. Neurochem Res 33:2035-2043.

Yirmiya R, Winocur G, Goshen I (2002) Brain interleukin-1 is involved in spatial memory and passive avoidance conditioning. Neurobiol Learn Mem 78:379-389. 